\title{
Top Concerns of Technical Services Staff
}

Summary notes submitted by Christa Strickler, Associate Professor of Library Science, Wheaton College

Moderated by Richard Lammert, Technical Services and Systems Librarian, Concordia Theological Seminary Fort Wayne

ABSTRACT The annual conversation group sponsored by the Technical Services Interest Group provides an opportunity for library workers in technical services areas-or in any area of library work-an opportunity to discuss anything that anyone considers a top concern for technical services staff. Participation by persons other than those in technical services area is encouraged, since the work in technical services ultimately influences work in all other areas of the library.

Twenty-one people logged into the session of the annual "Top Concerns of Technical Services Staff” held on June 23, 2021. In the open discussion, the attendees discussed the following topics:

\section{TOPIC: EBSCO E-BOOK RECORDS}

The records provided with consortial purchases of e-books from EBSCO only contain BISAC subject headings. Even though the record contains an OCLC number linking to a record with Library of Congress Subject Headings, those more-detailed access points are not included in the EBSCO record. Proposed solutions included inquiring with EBSCO about the subject heading removal, manually importing the records using the OCLC numbers provided in the EBSCO records, or using MarcEdit to extract the OCLC numbers, do a batch search in OCLC Connexion, and bulk import the records.

\section{TOPIC: STUDENT WORKER TRAINING}

What methods do different libraries use for training student workers? Is one-on-one training the norm, or do Atla members also use tools such as Trello or learning management systems? Some attendees referred to Jude Morrissey's presentation on "Making Use of Your LMS for Student Staff Training \& Support” (a Listen-and-Learn session earlier in this conference) as providing good ideas for using 
options such as quizzes within the LMS. Trello works for some but not others, with its effectiveness partly depending on the complexity and flexibility of the setup (simpler is better for some) and the nature of the work, with the predictability of cataloging tasks being better suited to Trello than the more volatile nature of circulation work.

\section{TOPIC: ADVOCATING FOR TECHNICAL SERVICES WORK}

It can be challenging to advocate for technical services work when one also has public services duties to manage. One suggestion is to explain how technical services work impacts the public services roles, such as searching the catalog. One can show how what one is doing in technical services adds values to the records. Another suggestion is to advocate for policies that show value for technical services work, such as ensuring that technical services student workers are not borrowed for public services work. It also helps to have conversations with one's supervisor about priorities so that there is agreement on whether timeliness, quality, or quantity of work is the most valued, since one can only manage two of the three at a time. Others also suggested tracking which tasks are done or the time spent on tasks so that one can demonstrate which activities will not be completed if one has to spend more time on public services work. Additionally, cataloging roles often include a lot of collaboration through programs such as NACO, CONSER, BIBCO, and OCLC shared cataloging. These shared programs are so embedded in our work that administrators may expect that if we reduce cataloging time to focus on public services tasks, the slack will simply be taken up by other institutions.

\section{TOPIC: MIGRATING TO A NEW INTEGRATED LIBRARY SYSTEM}

In a migration from Alma to OCLC's WorldShare Management System, tracking which records are for electronic materials and which are for print is challenging. A suggestion from OCLC is to ensure that records for electronic materials include a $\$ \mathrm{~h}$ in the 245 field to assist in record identification, but this does not validate in RDA records. For now, the solution has been to use a 590 field.

\section{TOPIC: RECORD ENHANCEMENTS IN OCLC}

When enhancing a local bibliographic record, it is sometimes not possible to transfer those enhancements to the master record in OCLC because permissions do not allow it. It was noted that OCLC is expanding the fields that may be updated in a PCC record. 